\title{
Pacing and decision-making in sport and exercise: the roles of perception and action in the regulation of exercise intensity
}

Benjamin L. M. Smits ${ }^{1}$, Gert-Jan Pepping ${ }^{1,2}$, Florentina J. Hettinga ${ }^{1,3}$

${ }^{1}$ University of Groningen, University Medical Center Groningen, Center for Human Movement Sciences, Groningen, the Netherlands

${ }^{2}$ Australian Catholic University, School of Exercise Sciences, Melbourne, Australia.

${ }^{3}$ University of Essex, School of Biological Sciences, Centre of Sport and Exercise Sciences, Colchester, UK

Running title: Pacing and decision-making

\section{Corresponding author:}

Florentina J. Hettinga, Ph.D.

University of Essex, School of Biological Sciences, Centre of Sport and Exercise Sciences

Wivenhoe Park

CO4 3SQ Colchester, UK

Email: fjhett@essex.ac.uk; fhettinga@hotmail.com

Tel: +441206876503

Fax: +441206873885

Word count (for text only, exclusive of title, abstract, references, tables, and figures legends): 6064. 


\begin{abstract}
In pursuit of optimal performance, athletes and physical exercisers alike have to make decisions about how and when to invest their energy. The process of pacing has been associated with the goal-directed regulation of exercise intensity across an exercise bout. The current review explores divergent views on understanding underlying mechanisms of decision-making in pacing. Current pacing literature provides a wide range of aspects that might be involved in the determination of an athlete's pacing-strategy, but lack in explaining how perception and action are coupled in establishing behaviour. In contrast, decision-making literature rooted in the understanding that perception and action are coupled provides refreshing perspectives on explaining the mechanisms that underlie natural interactive behaviour. Contrary to the assumption of behaviour that is managed by a higher order governor that passively constructs internal representations of the world, an ecological approach is considered. According to this approach, knowledge is rooted in the direct experience of meaningful environmental objects and events in individual-environment processes. To assist a neuropsychological explanation of decision-making in exercise-regulation, the relevance of the affordance competition hypothesis is explored. By considering pacing as a behavioural expression of continuous decision-making, new insights on underlying mechanisms in pacing and optimal performance can be developed.
\end{abstract}




\section{INTRODUCTION}

In pursuit of optimal performance, athletes and physical exercisers alike have to make decisions about how and when to invest their energy. In sport and exercise physiology this phenomenon is also known as pacing. In the performance-oriented sports context, pacing has been associated with the regulation of exercise intensity throughout an exercise bout based on circumstantial factors, in order to maintain internal homeostasis $[1,2]$ and/or avoiding early exhaustion [3, 4]. The circumstantial factors are a combination of interoceptive (i.e. physiological, psychological, and/or biomechanical) and exteroceptive (i.e. environmental) factors [5]. Additionally, the pacing-strategy athletes adopt throughout the exercise bout is related to personal goals and knowledge of the likely demands of the bout [6]. Many studies have shown how performance and pacing are related [7-10], how self-paced performances involve predetermined exercise templates [10-14], and how pacing strategies can be predicted based on theoretical modelling [10, 15-17]. It has been found that athletes tend to self-select strategies closely related to their natural disposition for exercise [18] and that forced adoption of an externally paced intensity is more physically demanding compared to self-pacing [14]. To identify underlying mechanisms that are relevant in the regulation of an athlete's exercise intensity, the current review considered both pacing and decision-making literature in the context of the potential roles of perception and action in the regulation of exercise intensity.

Decision-making has been defined as the capability of individuals to select functional actions to achieve a specific task goal from a number of action-possibilities [19]. Action-selection is an important component in the process of decision-making. Certainty about exercise duration, knowledge of the end point, and the physical sensations of effort and fatigue have all been associated with adequate pacing, and their integration seems guiding in appropriate action-selection [20]. In the following, we will first provide an overview of how perception and action are treated in the current literature on exercise-regulation and pacing. Next, we will review the literature on decision-making and note important similarities between certain approaches to decision-making and pacing. Based on these similarities and their associated short comings in integrating a coupling between perception and action in the regulation of exercise intensity, we will introduce and explore an ecological approach to understanding pacing and decision-making in the regulation of exercise intensity. To contribute to the neuropsychology of decision-making in exercise-regulation we end with introducing a novel hypothesis inspired by an ecological approach on the neural integration of information in the context of pacing and decisionmaking.

\section{PERCEPTION AND ACTION IN PACING}

In pacing literature perception is generally investigated by focussing on processes generally accepted to be affiliated to perception, such as sensations accompanying prolonged exercise, and internal proxies for perception, such as afferent signals. In particular the sensations of effort, whole body exertion, and fatigue are phenomena that are much studied in relation to pacing.

\subsection{Perception in Pacing: Fatigue and its Quantification}


Fatigue is an important aspect of pacing and performance, and has been associated with both an increase in the perceived effort necessary to exert a desired exercise intensity (also called sensation of fatigue or discomfort) and the eventual inability to produce that exercise intensity [21]. Adequate management of sensations of fatigue leads to optimal performance. Starting a race too fast risks early exhaustion, whereas starting too slow could conflict with performance goals [2]. In the case of developing physical exhaustion, sensations of fatigue are related to the interpretation of the effect of the current level of activity on future exercise capacity [22], while the regulation of a pace is associated with tolerating discomfort and knowledge of the likely task-demands [6]. Fatigue and accompanying perceptual processes might thus be important components for decision-making in pacing.

A popular way of measuring perceptions of fatigue and affiliated sensations, such as whole-body exertion, is by means of the rating of perceived exertion (RPE) scale. This evaluation tool is mostly used in experimental settings [23-27]. RPE has been described to be related to the circumstantial factors (see Table 1) that provide afferent input for a mechanism that allows an athlete to complete an exercise task within certain metabolic and/or mechanical limits [25]. A number of studies have suggested the existence of a system in which the integration of sensory systems and previous experience takes place [28, 29]. According to Lambert and colleagues [28], for instance, the identification of significant changes in negative feedback controllers, the so called homeostats, suggests an active neural process aimed at prevention of exhaustion. It has been concluded that effort perception involves an integration of multiple afferent signals. Depending on the circumstances, a particular physiological signal may be markedly altered and become the dominant mediator of the overall RPE [25]. In contrast to the classic interpretation that RPE is a measure exclusively of exercise intensity [23], it is suggested that RPE is related to the duration of exercise that has been completed or that still remains [30].

\section{Please insert Table 1 about here}

\subsection{From Perception to Action}

Ulmer [2] proposed that exercise may be regulated by central calculations and efferent commands that attempt to couple metabolic and biomechanical limits of the body to the task demands in a process described as teleoanticipation. It is argued that a central programmer would function as an input/output black box to coordinate afferent and efferent pathways such that exercise intensity does not exceed exercise limits. However, no consensus on what constitutes these limiting factors of exercise exists [25].

In the 1920s, Hill and colleagues [63] proposed that human exercise was limited by a maximal cardiac output, which was reflected in lactic acid accumulation and/or myocardial ischemia. In the late 1990s, the Hillmodel was under debate, because it allowed no role for the brain in the regulation of exercise performance and protection of homeostasis [5, 64]. Noakes and colleagues proposed that homoeostasis is protected under all conditions through behaviour modification [5], and changes of speed stand in proportional relation to changes in the extent of skeletal muscle recruitment (e.g. allowing an end-spurt) [65]. Accordingly, the Central Governor model (CG-model) was introduced, in which the brain occupies a dominant control position [64]. The CG-model proposed that the development of physiological exhaustion is a relative rather than an absolute event, and sensations of fatigue are a symptom and not a physical state. Based on the integration of internal sensory signals and information from the environment, a subconscious governor brain region sets and regulates the exercise 
intensity by determining the mass of skeletal muscle that is recruited throughout the bout [66] and project the symptom of fatigue to the conscious brain [27]. This symptom acts as an additional conscious limiter of the exercise intensity. Finally, anticipatory pacing as proposed by Ulmer [2, 5] was rediscovered [67, 68], and incorporated in the CG-model. For decision-making in pacing, this means that sensations of fatigue are important, as well as a teleoanticipatory planning of the race based on knowledge of the likely demands of the remaining exercise-bout.

Several scientists have questioned the existence of a subconscious (dominant) control region in the brain regulating whole-body homeostasis and pacing, and alternative mechanisms have been proposed. Since physiological catastrophes can and do occur [1] and a variety of peripheral factors can impair muscle performance [69], it is suggested that the proposed dominant governor could at least be over-ridden. MacIntosh and Shahi [70] proposed a peripheral governor, working at the cellular level, which can reduce the muscle contraction by attenuating activation to avoid metabolic catastrophe. Marcora [71] suggested that deciding when to terminate exercise is done by the conscious brain without the need to include an additional subconscious entity. Task disengagement occurs when the effort required by the prolonged constant-power exercise is equal to the maximum effort the athlete is willing to exert, or when the athlete believes to have exerted a true maximal effort. Edwards and Polman [6, 72] regard a single control region in the subconscious brain as unlikely and subsequently proposed to consider the brain as a complex system of neural communications, regulated by consciousness. In a nutshell, they assumed that: 1) the conscious brain is the central governor, 2) subconsciousness can be considered as a state of subawareness within a conscious state, and 3) low levels of physical effort are regulated by the conscious brain but possibly at a level of automated subawareness. The bombarding of sensory negative cues, as a consequence of high intensity exercise, triggers the conscious awareness to control the performance [6,72].

All these proposals suppose that in some way sensations of fatigue, and a willingness to tolerate discomfort (in anticipation to future rewards [73]), are important in the process of action-regulation. However, whereas the body of knowledge of pacing is associated with the proposal that a subconscious governor brain region sets and regulates the exercise intensity, the importance and dominance of (specific regions in) the brain in regulating actions is increasingly challenged.

\subsection{The Selection of an Appropriate Pacing-Strategy}

Four important aspects of pacing in the context of perception and action-regulation can be extracted: 1) the goal of pacing is to complete the exercise bout without the development of exhaustion/disturbed homeostasis [74]; 2) the development of exhaustion is a relative event and sensations of fatigue are a symptom which acts as an additional conscious restrainer or modulator of the exercise intensity [27]; 3) RPE is the overall conscious perception of integrated physiological activity [27]; and 4) both recognising significant changes in homeostats [28] and fatigue [66] are part of an active neural process, the function of which is to prevent the development of exhaustion. In short, the regulation of an athlete's pace (action) seems to be associated with processes at the neural level, which are influenced by afferent signals (which influence perception). However, the literature does not address how perception and action merge $[3,72,75]$ and which underlying action-regulation processes occur. A serial linking between perception and action is advocated, requiring the need of an additional mechanism that can bridge an apparent void between the two, a perception/action-gap. A black box control 
system is suggested that secures homeostasis during exercise [2, 64]. However, the location of- and processes occurring associated with this controller are not understood yet. Different mechanisms are suggested at muscular level [70] as well as within the brain [64].

Recently, Roelands and colleagues [76] made a first attempt to determine underlying neurophysiological mechanisms involved in the complex skill of pacing. They linked fatigue to pacing and concluded that a complex interplay between different neurotransmitter systems potentially influences pacing during exercise. In pursuit of an understanding of the complex skill of pacing in a broad perspective, the current review now continuous the exploration of pacing from a more behavioural perspective, and considers the viewpoint that there is a more intimate link between perception and action than the serial links proposed so far. From this perspective, pacing is approached as a continuous process of decision-making. Before we set out this approach to pacing and decision-making however, we will provide a brief overview of the literature on decisionmaking in intermittent sports and show some important similarities between the dominant approach in research in pacing and those in research on decision-making and the short-comings in failing to consider the coupling of perception and action that follow from them.

\section{DECISION-MAKING IN SPORT AND EXERCISE}

During exercise, athletes are continuously required to make decisions. While most pacing literature focuses on endurance sports, research in the decision-making domain is mainly conducted in intermittent sports (e.g. team ball sports and racket sports [77-79]). Whereas in endurance sports, decision-making in response to interoception is relatively more dominant, in intermittent sports, decision-making is commonly related to exteroceptive influences in a continuously changing environment [80].

Research on the influence of physiological factors on decision-making during exercise has mainly been performed by looking at the effects of physical activity on cognitive decision-making performance measures. For instance, Tomporowski [81] reviewed the effects of acute bouts of exercise on adults cognitive performance and concluded that submaximal aerobic exercise performed for periods up to 60 minutes facilitated certain aspects of cognitive performance, whilst extended exercise leads to performance decrements. More recently, using metaanalytical approaches McMoris and colleagues [82] investigated the effects of acute and intermediate intensity exercise on the speed and accuracy of performance of working memory tasks. Exercise was found to demonstrate a small yet significant effect on cognition [83], in particular during moderate intensity exercise. A common finding was that in particular the speed of decision-making was improved whilst the accuracy of decisions was left unaffected by exercise. Fatigue has also been related to cognitive performance. In general, higher intensity levels of a primary task require a stronger supraspinal drive to compensate the more enhanced peripheral fatigue [84]. This negatively affects cognitive performance in a second cognitive dual task, which becomes more pronounced with fatigue.

In defining self-efficacy - an athlete's belief in the ability to perform a certain task - Bandura [85] included physiological states as a principal source of information. According to Bandura, people read their visceral arousal in stressful and taxing situations. In activities involving strength and stamina, sensations of fatigue and aches are indicators of physical inefficacy [85]. Processing visceral information is closely related to 
emotional and motivational aspects of behaviour. Baron and colleagues [4] suggested that Affective Load (AL) may contribute to the regulation of exercise intensity. The AL-scale indicates how positive and negative affective responses are relative to each other during exercise. The more positive the affective responses are, the greater the desire to maintain or to increase the exercise intensity will be and vice versa. Affective load thus might play a role in decision-making in pacing.

Whereas in pacing literature it is emphasized that the integration of knowledge of the likely demands of the remaining exercise-bout [6] and the physical sensations of effort and fatigue act as guiding in determining response-characteristics [20], descriptions of steps made during action-regulation/response-initiation in (intermittent) sports do not address the state of the body. For example, according to Tenenbaum [80], motor behaviour in competitive situations consists of encoding relevant environmental cues, processing the information through interactions between working- and long-term memory, making an action-related decision, and executing the action while leaving room for refinements and modifications.

In the context of the current review on decision-making in pacing, the usefulness of such a model of response-initiation in intermittent sports is questionable. For instance, it is important to consider the current physiological state, the consequences of possible actions on the future physiological state, and the likely demands of the remaining exercise-bout. Athletes may not always be able to refine their actions while perceiving significant discomfort [86].

\section{DECISION-MAKING IN THE REGULATION OF EXERCISE INTENSITY}

\subsection{Current Perspectives}

At every instant during exercise, the circumstances present athletes many opportunities and demands for action, which faces them with the problem of which action to select. The literature presented in this review thus far suggest that external information about objects in the world in combination with internal information about the current physiological state are used to select an appropriate action. Further, the literature suggests that athletes fit the actions they perform in anticipation to the behavioural needs (e.g. exhaustion avoidance or goal achievement). This involves specification of action-parameters, which requires information about the spatial relationships among objects and surfaces in the world, represented in a coordinate frame relative to the orientation, configuration, and state of the athlete's body [87]. Athletes continuously decide 'what to do' (actionselection) and 'how to do it' (action-specification) [88]. In order to accomplish this, the literature presented so far advocates a view of the brain as an information-processing system. In this view, by the time motor processing begins (action-specification), cognitive processes have decided what to do (action-selection), and a single motor program is prepared before movement execution $[89,90]$. This traditional information processing approach fits with the concept of a central control system that is responsible for decision-making in pacing. The input (perception) and output (action) of the control system are known, but no clarity exists about how perception and 
action are related to one another. Main explanations of how perception and action might be linked refer to an indecipherable entity (i.e. input/output black box), which is not further specified.

From an information-processing approach, three processes can be seen to serially follow each other before movements are executed, namely: 1) perception: the construction of internal representations of the world which are used as the input to cognitive systems; 2) cognition: bringing salient context-dependent information together in a temporary working memory buffer, manipulate representations to build complex knowledge, store and retrieve information from long-term memory, perform deductive reasoning, and make decisions; and 3) action: the motor systems are tools that implement action-plans chosen by cognitive processes [88]. The information processing approach was originally proposed as an explanation of complex human abilities of abstract problem solving [91, 92]. Information about the world must be obtained, and a great deal of computation must take place, before taking any external actions. Nowadays, scientists studying sensorimotor control also have the tendency to analyse behaviour as one of transforming input representations to output representations through a series of intermediate processing stages [88], as also in the literature on pacing [27]. Attempts to interpret neural data from the information-processing approach encounter several still not invalidated anomalies [88]. Moreover, the information processing approach does not explain how perception and action come together in the on-going regulation of exercise intensity.

\subsection{An Alternative Approach}

While considering an information processing approach, the internal processes that are most useful for guiding behaviour (action) are those that first passively construct internal representations of the world (perception) and then reflect upon it with some introspective, intelligent circuits (cognition) [88]. The complex performanceenvironment of athletes however, requires them to continuously modify on-going behaviour, evaluating alternative behaviour that may become available, and making trade-offs between choosing to persist in a given behaviour (e.g. current pace) and switching to a different one [88]. In addition, athletes' action capabilities will be affected by fatigue [93]. These complex and dynamic necessities will have to be incorporated in an account of decision-making in the regulation of exercise intensity, but have no place in the information processing view as it currently stands.

To accommodate for the complex demands on decision-making in the regulation of exercise intensity, in the current paper we put forward an alternative approach to studying decision-making in pacing, which is rooted in an ecological approach. In this approach the coupling of perception and action is seen as a process that mediates sensorimotor interaction in the here and now, on the basis of continuous streams of sensory information as well as prior knowledge and experiences [88,94]. A central notion within this approach is the concept of affordances, which refer to properties of the environment which can be detected as information to support an action, and which are related to an individual's ability to use it; action capabilities [94-96]. Instead of taking a Cartesian stance in which a higher order governor manages the behaviour of the body, it is assumed that internal processes in the mind are reciprocally linked to processes in the body and the environment in which the body acts. Decision-making is considered as a complex and temporally extended process, which does not characterise an individual as having made a decision prior to its behavioural expression [97, 98]. Instead, decision-making is considered as the actualization of affordances, the possibilities for action in the environment that athletes perceive and may act upon [94, 96, 99]. In dynamic situations, where on-going behaviour has to be continuously 
modified, action possibilities arise and vanish as a result of changing action capabilities and environmental demands. Because of the dynamic character of situations like these, and the according emergent nature of decisions, this approach has also been referred to as the ecological dynamics approach [98, 100-102].

The use of environmental and bodily information specifying affordances should not be considered in isolation for a given moment, but also in anticipation to factors such as knowledge about the likely taskdemands, personal goals, and the rules that make up many competitive sport situations. These sources of information are commonly associated with knowledge structures and memory processes inside the head [103]. From an ecological perspective, however, information is not stored in the head, but granted by or made available in a particular situation, for instance, through a history of similar situations, and over longer periods of time [94, 104-106]. With relevance to regulating exercise intensity, the perception of an affordance of the athlete's bodily state/capacity during a particular exercise event, in particular in anticipation to prior knowledge, is not an isolated moment but an episode in a number of nested long-term events that make up the on-going dynamics of the athlete's exercise-environment [104].

To conclude so far, the ecological approach presented provides a well-grounded alternative way of understanding decision-making in the regulation of exercise intensity [98, 107]. Further, if pacing could be approached as a behavioural expression of continuous decision-making, new insights in action-regulation and performance determinants in sports and exercise can be gained.

\subsection{Entering the Neuropsychology of Decision-Making: The Affordance Competition Hypothesis}

Traditional cognitive theories propose that in natural behaviour action-selection occurs before actionspecification. The theory of affordances proposes that during natural interactive behaviour action-selection and specification should be regarded as the same dynamic process $[99,108,109]$. The results of a number of studies in intermittent sports show that athletes are faced with situations where multiple actions are afforded simultaneously [102, 110-112]. To address how people deal with these situations, drawing on ideas from neuroscience and ecological psychology, Cisek and Kalaska proposed the affordance competition hypothesis (AC-hypothesis) [87, 88].

\section{Please insert Fig. 1 about here}

The AC-hypothesis, summarized in Fig. 1 [88], incorporates multiple ideas, such as the proposals that neural processing is continuous and not organized in distinct serial stages, and the parallel preparation of several potential actions whilst collecting evidence for selection between them [88]. In general terms, the hypothesis is that behaving in a natural environment involves continuous and simultaneous processes of interactions between environmental stimuli and an individual's action capabilities and needs. These interactional processes provide for the specification of potential actions, and the competition between potential actions while subjected to a variety of biasing influences such as rewards, costs, or risks. For action-specification, areas within, for instance, the dorsal visual systems have been shown to perform transformations that convert information about objects in sensory coordinates into the parameters of potential actions [87, 88]. Competition between potential actions is hypothesised to occur within the fronto-parietal cortex, while a variety of biasing influences are provided by prefrontal regions and the basal ganglia. The same brain areas that specified potential actions ultimately guide 
the execution of those actions. Recent studies have supported these suggestions [87, 113]. For example, it was found that when a monkey was presented with two opposite potential reaching actions, neural activity in the premotor cortex specified both directions simultaneously ([87]; see also Cisek \& Kalaska (2010) [88]). When information for selecting one action over the other became available, the activity of the chosen direction was strengthened while that of the unwanted direction was suppressed [87]. For an extensive overview of research that has examined the AC-hypothesis in neuropsychological and neurophysiological research the reader is referred to Cisek \& Kalaska (2010) [88].

The AC-hypothesis suggests that the precise order in which decisions appear across the cerebral cortex are highly task dependent. In support of this, it was found that in tasks requiring stimulus salience, such as a popout visual search task, parietal regions reflected the choice before prefrontal regions. Conversely, if a task involves biasing factors that require complex stimulus-rule conjunctions, such as conjunction search, prefrontal regions reflected the choice before propagating back to the parietal cortex [114]. In pacing it has been shown that sensory negative cues that accompany high intensity exercise can influence prefrontal regions and conscious awareness to influence performance. Regarding the existing literature on decision-making in pacing this is consistent with the idea proposed by Edwards and Polman that pacing control is distributed throughout the subconscious and conscious brain [6,72].

\section{DISCUSSION}

Over the last decades, studies from various approaches have contributed to the establishment of a wide range of aspects that might be involved in the determination of an athlete's pacing-strategy. The present review aimed to bring these findings together in a transcending theoretical pacing-framework, and to further understand mechanisms involved in pacing in the context of decision-making in action-regulation. Literature revealed that pacing is closely related to various interoceptive and exteroceptive circumstantial factors (i.e. psychological, physiological, biomechanical and environmental; Table 1) that are integrated and act as guiding in appropriate action-regulation. More specific, the importance of both neurophysiology [76] and behavioural mechanisms involving perception and action are emphasised. Although the importance of the brain is stressed, and references are given to a computing governor, explanations about how integration of the various factors takes place are not fully clear yet. Furthermore, analysis based on an information processing approach does not explain how perception and action are integrated in the continuous regulation of exercise intensity. An ecological approach to decision-making in pacing was considered in which perception and action are intrinsically linked. A central notion in this approach is that of affordances. To contribute to the neuropsychology of decision-making in exercise-regulation the affordance competition hypothesis (AC-hypothesis) was explored in which neural processing of internal and external information is continuous and the brain begins to prepare several actions in parallel while collecting evidence for selection.

Within the AC-hypothesis multiple potential actions compete through mutual excitation and inhibition. Relating this to pacing, the exciting and inhibiting cells which influence action-regulation should be involved in, or affected by, the process which is responsible for maximizing performance as well as preventing the development of exhaustion. The pacing-literature suggests that significant changes in homeostats and fatigue are 
involved in such a process. Furthermore, it has been proposed that the development of exhaustion is a relative event in which the sensation of fatigue should be regarded as a symptom, acting as an additional exercise intensity modulator. Fatigue, then, could well be related to information that specifies the degree that homeostasis is disturbed. This is in line with the proposal that RPE relates to the overall conscious perception of all the physiological activity in the body [27]. Hence, the relativity of the sensation of fatigue may be part of an individual's ability to cope with discomfort [4,93], which, in turn, could be a bias-factor during affordance competition.

In the pacing literature, several authors have stressed the importance of the brain, and numerous controlmechanisms are suggested [64, 71, 72]. The black box approach of a central governor [64] leaves much room to speculate on behavioural, neurophysiological, and neuropsychological mechanisms involved. It seems that the proposed dominant governor model is not explaining all processes associated with fatigue and pacing that occur in daily life. As an alternative, it has been proposed that the regulation of physical effort is distributed across the conscious and subconscious brain [6,72]. Task disengagement would occur when the effort required by the prolonged constant-power exercise is equal to the maximum effort the athlete is willing to exert; or when the athlete believes to have exerted a true maximal effort [71]. These arguments imply that there is no specific region in the brain that is most important in pacing. Rather, internal processes in the mind are directly and reciprocally linked to processes in the body. Subsequently, pacing could be considered as the mediation-process of sensorimotor interaction in the here and now, on the basis of a continuous flow of perceptual information as well as prior knowledge and experiences. Hence, the current assumption that afferent and efferent pathways are coordinated in such a way that exercise intensity does not exceed the limits of the body [2] could be consistent with ideas that follow from an ecological approach, with the remark that neural processing is based on reciprocal perception/action-coupling and not organized in distinct serial stages within a governor region.

Recently, two RPE-based scores have been proposed which attempt to understand action-regulation based on perception and (conscious) decision-making. Although no conclusive evidence for reliability and validation are estimated yet, these scores are valuable attempts to relate conscious sensations of fatigue to information from the body and the environment as well as to cognitive factors such as motivation, and could serve as a catalyst in exploring the potential/usefulness of RPE-data in 'decision-making in pacing' research. The Hazard-score [48] is the product of the momentary RPE and the fraction of race distance remaining, incorporating both internal cues as well as external information. A high score means homeostatic disturbance, facing the choice of reducing intensity or not finishing. Swart and colleagues [20] proposed that physical sensations of effort act as the template regulating performance during exercise and that deviation from that template produces an increase in the sense of mental effort. The latter was measured with Task Effort and Awareness score (TEA-score). It was concluded that the conscious decision of whether to maintain or change the current workload could be the outcome of a balance between motivation, affect, and sense of mental effort [20]. Both the Hazard- and TEA-score (in which RPE is incorporated) could contribute to research on the influence of fatigue in pacing and decision-making, because of their attempt to understand action-regulation based on perception and (conscious) decision-making.

In animal behaviour research, attention has been given to the role of energy expenditure in decisionmaking/action-regulation. Whereas in predation risk insignificant situations animals choose where and how to forage, and what to eat, solely by measuring energy return from food per unit energy or time of searching [115- 
119], in more precarious situations they reduce their rate of food intake [120-122] or sacrifice foraging efficiency by raising their energy expenditure [123] in order to lower predation risk. Finally, some predator-species have longer chase-distances in successful than in unsuccessful hunts and any longer unsuccessful hunts are generally initiated by juveniles [124]. This indicates that they are able to gauge their chances of success, decide to give up early if failure is predicted to conserve energy for further hunts, and, as with pacing athletes, experience-based anticipation is a key factor in action-regulation [72]. These studies show that research in animal behaviour may also provide more insights in underlying neural action-regulation processes involved in pacing. It is, for instance, proposed that the anterior cingulate cortex (ACC) is involved in making decisions about the amount of effort to invest for rewards [125]; the orbitofrontal cortex affects decision-time to wait for rewards [125]; and activity in the ACC and mesolimbic dopamine pathways influence decision-making when facing easily obtainable small rewards and less accessible greater rewards [126]. So, with the suggestions made in neuropsychological and neurophysiological research in human and animal, brain regions can be identified that may contribute to the biasing process while making a trade-off between choosing to persist in a given activity or pace and switching to a different one.

Thus far, the AC-hypothesis has mainly been engaged with an understanding of environmentally guided behaviour, with a focus on the role of perceptual information in the environment of the performer. Research on the role of the athlete's action-capabilities in the coming about of decisions on the other hand is relatively sparse [127]. In order to provide a better understanding of both environmental and action-capabilities influences, current knowledge needs to be enriched with neurophysiological findings from neurotransmitter-studies and studies on interoceptive influences in action-regulation, such as exercise induced fatigue [76]. As an example, it has been suggested that during physical fatigue the motor output from the primary motor cortex is primarily based on the degree of balance between sensory input from the peripheral system (inhibition) and motivational input (facilitation) [128] and that the mid/anterior insular cortex - involved in the evaluation of homeostatic processes - might not only integrate and evaluate sensory information from the periphery, but also act in communication with the motor cortex [129]. These examples support the suggestion that there are relational body-environment (i.e. affordance-based) factors that influence action-regulation in order to maintain homeostasis and/or regulate sensations of fatigue, which is associated with pacing.

Though controlled experimental studies have led to a large body of knowledge on pacing, fatigue and performance, we would like to stress the importance of research incorporating the interaction with the environment based on the present review. There are theoretical concerns over the representativeness of the design in studies of decision-making in sport and exercise [130-132]. This concern specifically refers to the arrangement of conditions in an experiment so that they represent the behavioural context to which the results are intended to apply. These concerns might also be relevant for pacing-research in which athletes are often removed from their natural exercise-environment, and are placed in a highly controlled and possibly impoverished laboratory setting. For instance, in many studies participants perform on stationary exerciseequipment. Unlike in natural unconstrained behaviour, most features of the sensory input are deliberately made independent from the athlete's actions; the response in a given moment usually does not determine the stimulus in the next moment. Although such settings are often designed based on strong methodological assumptions, they may have unintentionally altered the behavioural processes under investigation such that the results from a specific experiment are not representative of the functional behaviours in participants' natural environments. For 
instance, a recent study considered the effects of visual information on perceptual experience during exercise [133]. Results showed that variations in environmental stimuli's speed, such as when accelerating or decelerating during races, influence both perception and action. The provision of a slower optic flow, that is, slower speed of the provided video footage in comparison to true cycled speed, was being associated with lower RPE together with higher power output as a behavioural response [133]. Ideas emanating from the approaches presented in this review might aid the understanding of the correspondence between experimental task constraints and individual, behavioural, and functional settings outside the laboratory. Another observation in this context is that athletes tend to self-select strategies closely related to their natural disposition for exercise [18]. Hence, the behavioural process of pacing can vary between athletes. The tendency to average data in statistical analyses can thus mask observations of functional levels of performance variability across individual participants [134], and a focus on individual data might provide different perspectives.

Most of the literature reviewed has focused on pacing and decision-making in sports performance. In other performances however, such as those that can be found in daily life, physically active lifestyles, and medical and rehabilitation settings, the regulation of exercise intensity over a certain task is also important. Think, for instance, about patients with limited energy stores or complaints of fatigue, or about an individual that is starting to pick up a new exercise regime. For these individuals it is important to identify meaningful performer-environment relationships for pacing and how these relationships might change as a function of practice, training, or habituation. For example, research has shown that in repetitive endurance type activities self-selected, motivational, and stimulating music enhance affect, reduce ratings of perceived exertion, improve energy efficiency, leading to increased work output [135, 136]. Identifying affordances that can help participants overcome a strong urge (affordance) to stop continuation of their exercise program, especially in the early stages, can in this way be a very important application in health sciences.

\section{CONCLUSION}

The current review explored divergent views on understanding underlying mechanisms in the regulation of exercise intensity. Instead of assuming that a higher order governor manages behaviour by first passively construct internal representations of the world, an approach that assumes that decision-making is a behavioural expression of the perception of affordances was explored. Additionally, the AC-hypothesis was introduced which proposes that during natural interactive behaviour at a neuropsychological level action-selection and specification are one and the same dynamic process. The use of ecological principles as a background in research in the field of sport and exercise may offer additional theoretical means to address the interdependence of perception and action and individual differences in the regulation of exercise intensity. The examination of pacing from this perspective could serve as a catalyst for gaining knowledge about how the many described circumstantial factors influence exercise intensity regulation, as well as how to set appropriate pacing strategies for the achievement of demanding goals in sports and exercise, medical and rehabilitation contexts, as well as daily life. 


\section{ACKNOWLEDGEMENTS}

No sources of funding were used to assist in the preparation of this review. The authors have no potential conflicts of interest that are directly relevant to the content of this review. 


\section{CAPTIONS}

Table 1 Summary of research investigating factors that are related to RPE, divided into the four pacing factor related categories

Fig. 1 Summary of the affordance competition hypothesis in the context of visually-guided movement. The filled dark blue arrows represent processes of action-specification. These are launched by the occipital cortex and go into the direction of the premotor cortex via the dorsal visual stream; suggesting that this stream mainly mediates visually guided actions, instead of building a unified representation of the world. Polygons represent three neural populations along the stream, which are depicted as maps where the lightest regions correspond to peaks of tuned activity. Peaks that appear simultaneously within a single cortical region compete for further processing. This is biased by input from the basal ganglia and prefrontal cortical regions (red double-line arrows) that collect information for action-selection. Cells with similar parameter preferences excite each other, while cells with different preferences inhibit each other. If activity associated with a given choice eventually becomes sufficiently strong by exceeding a certain threshold, it suppresses its opponents and conclusively wins the competition. The final selected action is released into execution and causes overt feedback through the environment (dotted blue arrow) as well as internal predictive feedback through the cerebellum [87, 88]. Reproduced from Cisek and Kalaska [88], with permission 


\section{REFERENCES}

1. Esteve-Lanao J, Lucia A, Foster C. How do humans control physiological strain during strenuous endurance exercise? PloS one. 2008;3(8):e2943.

2. Ulmer HV. Concept of an extracellular regulation of muscular metabolic rate during heavy exercise in humans by psychophysiological feedback. Experientia. 1996;52(5):416-20.

3. St Clair Gibson A, Lambert EV, Rauch LHG, Tucker R, Baden DA, Foster C, et al. The role of information processing between the brain and peripheral physiological systems in pacing and perception of effort. Sports Med. 2006;36(8):705-22.

4. Baron B, Moullan F, Deruelle F, Noakes TD. The role of emotions on pacing strategies and performance in middle and long duration sport events. Br J Sports Med. 2011;45(6):511-7.

5. Noakes TD. Time to move beyond a brainless exercise physiology: The evidence for complex regulation of human exercise performance. Appl Physiol Nutr Metab. 2011;36(1):23-35.

6. Edwards AM, Polman RCJ. Pacing and awareness: Brain regulation of physical activity. Sports Medicine. 2013;43(9):1-8.

7. Nikolopoulos V, Arkinstall MJ, Hawley JA. Pacing strategy in simulated cycle time-trials is based on perceived rather than actual distance. Journal of Science and Medicine in Sport. 2001;4(2):212-9.

8. Garland SW. An analysis of the pacing strategy adopted by elite competitors in $2000 \mathrm{~m}$ rowing. Br J Sports Med. 2005;39(1):39-42.

9. Hettinga FJ, De Koning JJ, Broersen FT, Van Geffen P, Foster C. Pacing strategy and the occurrence of fatigue in 4000-m cycling time trials. Med Sci Sports Exerc. 2006;38(8):1484-91.

10. Hettinga FJ, De Koning JJ, Schmidt LJI, Wind NAC, MacIntosh BR, Foster C. Optimal pacing strategy: From theoretical modelling to reality in 1500-m speed skating. Br J Sports Med. 2011;45(1):30-5.

11. Albertus Y, Tucker R, St Clair Gibson A, Lambert EV, Hampson DB, Noakes TD. Effect of distance feedback on pacing strategy and perceived exertion during cycling. Med Sci Sports Exerc. 2005;37(3):461-8.

12. Eston R, Faulkner J, St Clair Gibson A, Noakes TD, Parfitt G. The effect of antecedent fatiguing activity on the relationship between perceived exertion and physiological activity during a constant load exercise task. Psychophysiology. 2007;44(5):779-86.

13. Joseph T, Johnson B, Battista RA, Wright G, Dodge C, Porcari JP, et al. Perception of fatigue during simulated competition. Med Sci Sports Exerc. 2008;40(2):381-6.

14. Lander PJ, Butterly RJ, Edwards AM. Self-paced exercise is less physically challenging than enforced constant pace exercise of the same intensity: Influence of complex central metabolic control. Br J Sports Med. 2009;43(10):789-95.

15. Van Ingen SGJ, De Koning JJ, De Groot G. A simulation of speed skating performances based on a power equation. Med Sci Sports Exerc. 1990;22(5):718-28.

16. De Koning JJ, Bobbert MF, Foster C. Determination of optimal pacing strategy in track cycling with an energy flow model. Journal of Science and Medicine in Sport. 1999;2(3):266-77.

17. Hettinga FJ, De Koning JJ, Hulleman M, Foster C. Relative importance of pacing strategy and mean power output in 1500-m self-paced cycling. Br J Sports Med. 2012;46(1):30-5. 
18. Hansen EA, Andersen JL, Nielsen JS, Sjøgaard G. Muscle fibre type, efficiency, and mechanical optima affect freely chosen pedal rate during cycling. Acta Physiol Scand. 2002;176(3):185-94.

19. Hastie R. Problems for judgment and decision making. Annu Rev Psychol. 2001;52(1):653-83.

20. Swart J, Lindsay TR, Lambert MI, Brown JC, Noakes TD. Perceptual cues in the regulation of exercise performance-physical sensations of exercise and awareness of effort interact as separate cues. Br J Sports Med. 2012;46(1):42-8.

21. Davis JM, Bailey SP. Possible mechanisms of central nervous system fatigue during exercise. Med Sci Sports Exerc. 1997;29(1):45-57.

22. Noakes TD, St Clair Gibson A, Lambert EV. From catastrophe to complexity: A novel model of integrative central neural regulation of effort and fatigue during exercise in humans. Br J Sports Med. 2004;38(4):511-4.

23. Borg GA. Perceived exertion as an indicator of somatic stress. Scand J Rehabil Med. 1970;2(2):92-8.

24. Borg GA. Psychophysical bases of perceived exertion. Med Sci Sports Exerc. 1982;14(5):377-81.

25. Hampson DB, St Clair Gibson A, Lambert MI, Noakes TD. The influence of sensory cues on the perception of exertion during exercise and central regulation of exercise performance. Sports Med. 2001;31(13):935-52.

26. Craig AD. Interoception: The sense of the physiological condition of the body. Curr Opin Neurobiol. 2003;13(4):500-5.

27. St Clair Gibson A, Noakes TD. Evidence for complex system integration and dynamic neural regulation of skeletal muscle recruitment during exercise in humans. Br J Sports Med. 2004;38(6):797-806.

28. Lambert EV, St Clair Gibson A, Noakes TD. Complex systems model of fatigue: Integrative homoeostatic control of peripheral physiological systems during exercise in humans. Br J Sports Med. 2005;39(1):52-62.

29. Morgan WP, Pollock ML. Psychologic characterization of the elite distance runner. Ann N Y Acad Sci. 1977;301(1):382-403.

30. Noakes TD. Rating of perceived exertion as a predictor of the duration of exercise that remains until exhaustion. Br J Sports Med. 2008;42(7):623-4.

31. Edwards R, Melcher A, Hesser C, Wigertz O, Ekelund LG. Physiological correlates of perceived exertion in continuous and intermittent exercise with the same average power output. Eur J Clin Invest. 1972;2(2):108-14.

32. Borg GA. Perceived exertion: A note on "history" and methods. Med Sci Sports. 1973 Summer;5(2):90-3.

33. Sargeant AJ, Davies CT. Perceived exertion during rhythmic exercise involving different muscle masses. J Hum Ergol. 1973;2(1):3-11.

34. Skinner JS, Hutsler R, Bergsteinova V, Buskirk ER. Perception of effort during different types of exercise and under different environmental conditions. Med Sci Sports. 1973;5(2):110-5.

35. Stamford B. Validity and reliability of subjective ratings of perceived exertion during work. Ergonomics. 1976;19(1):53-60.

36. Hugh Morton R. Deception by manipulating the clock calibration influences cycle ergometer endurance time in males. Journal of Science and Medicine in Sport. 2009;12(2):332-7.

37. Zamparo P, Perini R, Orizio C, Sacher M, Ferretti G. The energy cost of walking or running on sand. Eur J Appl Physiol Occup Physiol. 1992;65(2):183-7.

38. Robertson R, Gilcher R, Metz K. Central circulation and work capacity after red blood cell reinfusion under normoxia and hypoxia in women. Med Sci Sports. 1979;11:98. 
39. Robertson RJ. Central signals of perceived exertion during dynamic exercise. Med Sci Sports Exerc. 1982;14(5):390-6.

40. Boutcher SH, Trenske M. The effects of sensory deprivation and music on perceived exertion and affect during exercise. J Sport Exerc Psych. 1990;12:167-76.

41. Masters KS, Ogles BM. Associative and dissociative cognitive strategies in exercise and running: 20 years later, what do we know? Sport Psychol. 1998;12:253-70.

42. Knicker AJ, Renshaw I, Oldham ARH, Cairns SP. Interactive processes link the multiple symptoms of fatigue in sport competition. Sports Med. 2011;41(4):307-28.

43. Faulkner J, Parfitt G, Eston RG. The rating of perceived exertion during competitive running scales with time. Psychophysiology. 2008;45(6):977-85.

44. Poulus AJ, Docter HJ, Westra HG. Acid-base balance and subjective feelings of fatigue during physical exercise. Eur J Appl Physiol Occup Physiol. 1974;33(3):207-13.

45. Robertson RJ, Falkel JE, Drash AL, Swank A, Metz KF, Spungen SA, et al. Effect of blood pH on peripheral and central signals of perceived exertion. Med Sci Sports Exerc. 1986;18(1):114-22.

46. Hetzler RK, Seip RL, Boutcher SH, Pierce E, Snead D, Weltman A. Effect of exercise modality on ratings of perceived exertion at various lactate concentrations. Med Sci Sports Exerc. 1991;23(1):88-92.

47. Swart J, Lamberts RP, Lambert MI, Lambert EV, Woolrich RW, Johnston S, et al. Exercising with reserve: Exercise regulation by perceived exertion in relation to duration of exercise and knowledge of endpoint. Br $\mathrm{J}$ Sports Med. 2009;43(10):775-81.

48. De Koning JJ, Foster C, Bakkum A, Kloppenburg S, Thiel C, Joseph T, et al. Regulation of pacing strategy during athletic competition. PloS one. 2011;6(1):e15863.

49. Bonacci J, Vleck V, Saunders PU, Blanch P, Vicenzino B. Rating of perceived exertion during cycling is associated with subsequent running economy in triathletes. Journal of Science and Medicine in Sport. 2013;16(1):49-53.

50. Coyle EF, Montain SJ. Benefits of fluid replacement with carbohydrate during exercise. Med Sci Sports Exerc. 1992;24:324-30.

51. Pandolf KB, Kamon E, Noble BJ. Perceived exertion and physiological responses during negative and positive work in climbing a laddermill. J Sports Med Phys Fitness. 1978;18(3):227-36.

52. Noakes TD. Physiological models to understand exercise fatigue and the adaptations that predict or enhance athletic performance. Scand J Med Sci Sports. 2008;10(3):123-45.

53. Burgess ML, Robertson RJ, Davis JM, Norris JM. RPE, blood glucose, and carbohydrate oxidation during exercise: Effects of glucose feedings. Med Sci Sports Exerc. 1991;23(3):353-9.

54. Walsh RM, Noakes TD, Hawley JA, Dennis SC. Impaired high-intensity cycling performance time at low levels of dehydration. Int J Sports Med. 1994;15(7):392-8.

55. Noakes TD, Snow RJ, Febbraio MA. Linear relationship between the perception of effort and the duration of constant load exercise that remains. J Appl Physiol. 2004;96(4):1571-3.

56. Edwards AM, Mann ME, Marfell-Jones MJ, Rankin DM, Noakes TD, Shillington DP. Influence of moderate dehydration on soccer performance: Physiological responses to $45 \mathrm{~min}$ of outdoor match-play and the immediate subsequent performance of sport-specific and mental concentration tests. Br J Sports Med. 2007;41(6):385-91. 
57. Lima-Silva A, De-Oliveira F, Nakamura F, Gevaerd M. Effect of carbohydrate availability on time to exhaustion in exercise performed at two different intensities. Braz J Med Biol Res. 2009;42(5):404-12.

58. Wilmore JH. Influence of motivation on physical work capacity and performance. J Appl Physiol. 1968;24(4):459-63.

59. Lehmann G, Straub H, Szakall A. Pervitin als leistungssteigerndes mittel. Eur J Appl Physiol Occup Physiol. 1939;10(6):680-91.

60. Alles GA, Feigen GA. The influence of benzedrine on work-decrement and patellar reflex. Am J Physiol. 1942;136(3):392-400.

61. Roush ES. Strength and endurance in the waking and hypnotic states. J Appl Physiol. 1951;3(7):404-10.

62. Ikai M, Steinhaus AH. Some factors modifying the expression of human strength. J Appl Physiol. $1961 ; 16(1): 157-63$.

63. Hill AV, Long CNH, Lupton H. Muscular exercise, lactic acid, and the supply and utilisation of oxygen. Proc R Soc Lond B Biol Sci. 1924;97(681):84-138.

64. Noakes TD. 1996 JB wolffe memorial lecture. challenging beliefs: Ex africa semper aliquid novi. Med Sci Sports Exerc. 1997;29(5):571-90.

65. Tucker R, Bester A, Lambert E, Noakes TD, Vaughan CL, St Clair Gibson A. Non-random fluctuations in power output during self-paced exercise. Br J Sports Med. 2006;40(11):912-7.

66. Noakes TD, St Clair Gibson A. Logical limitations to the "catastrophe" models of fatigue during exercise in humans. Br J Sports Med. 2004;38(5):648-9.

67. Kay D, Marino FE, Cannon J, St Clair Gibson A, Lambert MI, Noakes TD. Evidence for neuromuscular fatigue during high-intensity cycling in warm, humid conditions. Eur J Appl Physiol. 2001;84(1):115-21.

68. Tucker R, Rauch L, Harley YXR, Noakes TD. Impaired exercise performance in the heat is associated with an anticipatory reduction in skeletal muscle recruitment. Pflugers Arch. 2004;448(4):422-30.

69. Weir JP, Beck TW, Cramer JT, Housh TJ. Is fatigue all in your head? A critical review of the central governor model. Br J Sports Med. 2006;40(7):573-86.

70. MacIntosh BR, Shahi MRS. A peripheral governor regulates muscle contraction. Applied Physiology, Nutrition, and Metabolism. 2010;36(1):1-11.

71. Marcora SM. Do we really need a central governor to explain brain regulation of exercise performance? Eur J Appl Physiol. 2008;104(5):929-31.

72. Edwards AM, Polman RCJ. Pacing in sport and exercise: A psychophysiological perspective. New York: Nova Science Publishers; 2012.

73. Cabanac M. Exertion and pleasure from an evolutionary perspective. In: Ekkekakis E, editor. Psychobiology of physical activity. Champaign, IL: Human Kinetics; 2006. p. 79-89.

74. Noakes TD. Testing for maximum oxygen consumption has produced a brainless model of human exercise performance. Br J Sports Med. 2008;42(7):551-5.

75. Abbiss CR, Laursen PB. Describing and understanding pacing strategies during athletic competition. Sports Med. 2008;38(3):239-52.

76. Roelands B, De Koning JJ, Foster C, Hettinga FJ, Meeusen R. Neurophysiological determinants of theoretical concepts and mechanisms involved in pacing. Sports Medicine. 2013;43(5):301-11. 
77. Abernethy B. Visual search strategies and decision-making in sport. International Journal of Sport Psychology. 1991;22(3-4):189-210.

78. Gréhaigne JF, Godbout P, Bouthier D. The teaching and learning of decision making in team sports. Quest. 2001;53(1):59-76.

79. Baker J, Cote J, Abernethy B. Sport-specific practice and the development of expert decision-making in team ball sports. Journal of applied sport psychology. 2003;15(1):12-25.

80. Tenenbaum G. Expert athletes: An integrated approach to decision making. In: Starkes JL, Ericsson KA, editors. Expert performance in sports. Champaign, IL: Human Kinetics; 2003. p. 191-218.

81. Tomporowski PD. Effects of acute bouts of exercise on cognition. Acta Psychol. 2003;112(3):297-324.

82. McMorris T, Sproule J, Turner A, Hale BJ. Acute, intermediate intensity exercise, and speed and accuracy in working memory tasks: A meta-analytical comparison of effects. Physiol Behav. 2011;102(3):421-8.

83. McMorris T, Hale BJ. Differential effects of differing intensities of acute exercise on speed and accuracy of cognition: A meta-analytical investigation. Brain Cogn. 2012;80(3):338-51.

84. Zijdewind I, Van Duinen H, Zielman R, Lorist MM. Interaction between force production and cognitive performance in humans. Clinical Neurophysiology. 2006;117(3):660-7.

85. Bandura A. Self-efficacy mechanism in human agency. Am Psychol. 1982;37(2):122-47.

86. Stoter IK, MacIntosh BR, Fletcher JR, Pootz S, Zijdewind I, Hettinga FJ. The effect of pacing strategy on muscle fatigue and technique in $1500 \mathrm{~m}$ speed skating and cycling. 17th Annual Congress of the ECSS. 2012(167).

87. Cisek P. Cortical mechanisms of action selection: The affordance competition hypothesis. Philosophical Transactions of the Royal Society B. 2007;362(1485):1585-99.

88. Cisek P, Kalaska JF. Neural mechanisms for interacting with a world full of action choices. Annu Rev Neurosci. 2010;33:269-98.

89. Miller GA, Galanter E, Pribram KH. Plans and the structure of behavior. New York: Holt, Rinehart and Winston; 1960.

90. Keele SW. Movement control in skilled motor performance. Psychol Bull. 1968;70(6):387-403.

91. Newell A, Simon HA. Human problem solving. Englewood Cliffs, NJ: Prentice-Hall; 1972.

92. Pylyshyn ZW. Computation and cognition: Towards a foundation for cognitive science. Cambridge, MA: MIT Press; 1984.

93. Jones G. What is this thing called mental toughness? an investigation of elite sport performers. Journal of Applied Sport Psychology. 2002;14(3):205-18.

94. Gibson JJ. The ecological approach to visual perception. Boston: Houghton Mifflin; 1979.

95. Gibson EJ, Pick AD. An ecological approach to perceptual learning and development. New York: Oxford University Press; 2000.

96. Gibson JJ. The concept of affordances. In: Shaw R, Bransford J, editors. Perceiving, acting, and knowing. Hillsdale: NJ: Erlbaum; 1977. p. 67-82.

97. Beer RD. The dynamics of active categorical perception in an evolved model agent. Adapt Behav. 2003;11(4):209-43. 
98. Araujo D, Davids K, Hristovski R. The ecological dynamics of decision making in sport. Psychol Sport Exerc. 2006;7(6):653-76.

99. Smith J, Pepping G-J. Effects of affordance perception on the initiation and actualization of action. Ecological Psychology. 2010;22(2):119-49.

100. Headrick J, Davids K, Renshaw I, Araújo D, Passos P, Fernandes O. Proximity-to-goal as a constraint on patterns of behaviour in attacker-defender dyads in team games. J Sports Sci. 2012;30(3):247-53.

101. Travassos B, Araújo D, Davids K, Vilar L, Esteves P, Vanda C. Informational constraints shape emergent functional behaviours during performance of interceptive actions in team sports. Psychol Sport Exerc. 2012;13(2):216-23.

102. Barsingerhorn AD, Zaal FTJM, de Poel HJ, Pepping G-J. Shaping decisions in volleyball: An ecological approach to decision-making in volleyball passing. International Journal of Sport Psychology. 2013;44(3):197214.

103. Williams AM. Perceptual skill in soccer: Implications for talent identification and development. J Sports Sci. 2000;18(9):737-50.

104. Schmidt RC. Scaffolds for social meaning. Ecological psychology. 2007;19(2):137-51.

105. Chemero A. Radical embodied cognitive science. Cambridge: MIT press; 2009.

106. Withagen R, Chemero A. Naturalizing perception. Theory \& Psychology. 2009;19(3):363-89.

107. Turvey MT, Shaw RE. Toward an ecological physics and a physical psychology. In: Solso RL, Massaro DW, editors. The science of the mind: 2001 and beyond. New York: Oxford University Press; 1995. p. 144-72.

108. Smith J, Zaal FJTM, Pepping G-J. In: Emergence of grasping: The transition between 2-digit and 3-digit grip configurations. Poster presented at mastery of manual skills; April 2012; Groningen, The Netherlands. University Medical Center Groningen, University of Groningen; 2012.

109. Smith J, Zaal FJTM, Pepping G-J. Emergence of grasping: The transition between 2-digit and 3-digit grip configurations. Manuscript submitted for publication. 2013.

110. Pinder RA, Davids K, Renshaw I. Metastability and emergent performance of dynamic interceptive actions. Journal of Science and Medicine in Sport. 2012;15(5):437-43.

111. Pepping G-J, Heijmerikx J, de Poel HJ. Affordances shape pass kick behavior in association football: Effects of distance and social context. Revista de Psicologia del Deporte. 2011;20(2):709-27.

112. Hristovski R, Davids K, Araújo D, Button C. How boxers decide to punch a target: Emergent behaviour in nonlinear dynamical movement systems. Journal of Sports Science and Medicine. 2006;5(CSSI):60-73.

113. Cui H, Andersen RA. Posterior parietal cortex encodes autonomously selected motor plans. Neuron. 2007;56(3):552-9.

114. Buschman TJ, Miller EK. Top-down versus bottom-up control of attention in the prefrontal and posterior parietal cortices. Science. 2007;315(5820):1860-2.

115. Charnov EL. Optimal foraging: Attack strategy of a mantid. Am Nat. 1976;110(971):141-51.

116. Krebs JR, Erichsen JT, Webber MI, Charnov EL. Optimal prey selection in the great tit (parus major). Anim Behav. 1977;25(1):30-8.

117. Goss-Custard JD. Optimal foraging and the size selection of worms by redshank, tringa totanus, in the field. Anim Behav. 1977;25(1):10-29.

118. Heinrich B. Bumblebee economics. Cambridge, MA: Harvard University Press; 1979. 
119. Pyke GH, Pulliam HR, Charnov EL. Optimal foraging: A selective review of theory and tests. Q Rev Biol. 1977;52(2):137-54.

120. Milinski M, Heller R. Influence of a predator on the optimal foraging behaviour of sticklebacks (gasterosteus aculeatus L.). Nature. 1978;275:642-55.

121. Stein RA. Behavioral response of prey to fish predators. In: Stroud RH, Clepper HE, editors. Predator-prey systems in fisheries management. Washington, DC: Sport Fishing Institute; 1979. p. 343-53.

122. Sih A. Optimal behavior: Can foragers balance two conflicting demands? Science. 1980;210(4473):1040-3.

123. Grubb TC, Greenwald L. Sparrows and a brushpile: Foraging responses to different combinations of predation risk and energy cost. Anim Behav. 1982;30(3):637-40.

124. Eaton RL. Hunting behavior of the cheetah. The Journal of Wildlife Management. 1970;34(1):56-67.

125. Rudebeck PH, Walton ME, Smyth AN, Bannerman DM, Rushworth MFS. Separate neural pathways process different decision costs. Nat Neurosci. 2006;9(9):1161-8.

126. Walton ME, Kennerley SW, Bannerman DM, Phillips PEM, Rushworth MFS. Weighing up the benefits of work: Behavioral and neural analyses of effort-related decision making. Neural Networks. 2006;19(8):1302-14.

127. Barsingerhorn AD, Zaal FTJM, Smith J, Pepping G-J. On possibilities for action: The past, present and future of affordance research. Avant. 2012;3(2):54-69.

128. Tanaka M, Watanabe Y. Supraspinal regulation of physical fatigue. Neuroscience and Biobehavioral Reviews. 2012;36(1):727-34.

129. Hilty L, Langer N, Pascual-Marqui R, Boutellier U, Lutz K. Fatigue-induced increase in intracortical communication between mid/anterior insular and motor cortex during cycling exercise. Eur $\mathrm{J}$ Neurosci. 2011;34(12):2035-42.

130. Araujo D, Davids K, Passos P. Ecological validity, representative design, and correspondence between experimental task constraints and behavioral setting. Ecological Psychology. 2007;19(1):69-78.

131. Araujo D, Davids K. Ecological approaches to cognition and action in sport and exercise: Ask not only what you do, but where you do it. International Journal of Sport Psychology. 2009;40(1):5.

132. Brunswik E. Perception and the representative design of psychological experiments. 2nd ed. Berkeley: University of California Press; 1956.

133. Parry D, Chinnasamy C, Micklewright D. Optic flow influences perceived exertion during cycling. J Sport Exerc Psychol. 2012;34(4):444-56.

134. Dicks M, Davids K, Button C. Individual differences in the visual control of intercepting a penalty kick in association football. Human movement science. 2010;29(3):401-11.

135. Karageorghis CI, Priest D-L. Music in the exercise domain: A review and synthesis (part I). International review of sport and exercise psychology. 2012;5(1):44-66.

136. Karageorghis CI, Terry PC, Lane AM, Bishop DT, Priest D-L. The BASES expert statement on use of music in exercise. J Sports Sci. 2012;30(9):953-6. 